\title{
How do the green components of urban green infrastructure influence the use of ecosystem services? Examples from Leipzig, Germany
}

\author{
Julia Palliwoda $\cdot$ Ellen Banzhaf · Jörg A. Priess
}

Received: 22 July 2019/Accepted: 25 March 2020/Published online: 6 April 2020

(C) The Author(s) 2020

\begin{abstract}
Context The pressure on remaining open spaces of urban green infrastructure (UGI) is high due to increasing urbanization and the multiple requirements of a diverse urban population. Thus, a good quality and high capacity for ecosystem services of UGI is crucial to support a good quality of life.

Objectives This study analyses the influence of tree cover and other green parameters like species richness on ecosystem service use in urban parks and green brownfields. The outcomes contribute to design and management of resilient UGI.

Methods We assessed the diversity of woody and herbaceous flowering species in 36 study sites with low, medium and high tree cover in the city of Leipzig, Germany. UGI users were counted, and randomly
\end{abstract}

Electronic supplementary material The online version of this article (https://doi.org/10.1007/s10980-020-01004-w) contains supplementary material, which is available to authorized users.

J. Palliwoda $(\bowtie) \cdot$ J. A. Priess

Department Computational Landscape Ecology,

Helmholtz Centre for Environmental Research (UFZ),

Permoser Straße 15, 04318 Leipzig, Germany

e-mail: julia.palliwoda@ufz.de

\section{E. Banzhaf}

Department Urban and Environmental Sociology,

Helmholtz Centre for Environmental Research (UFZ),

Permoser Straße 15, 04318 Leipzig, Germany selected visitors $(n=1750)$ were interviewed about their use of ecosystem services.

Results We found tree cover in urban parks negatively influencing physical interactions used by respondents. In parks with high tree cover, more respondents were benefitting from regulating services such as noise mediation or shade provision. Brownfield visitors preferred sites with low to medium tree cover, mainly for walking the dog but also for other ecosystem services. Plant species richness did not show significant influence.

Conclusions Tree cover in parks and brownfields can be a predictor for a range of ecosystem services typically used by visitors, highlighting how vegetation or green structures in UGI can be employed to steer the use. Brownfields provide additional space for complementary ecosystem service use, thus contributing to the avoidance of potential use conflicts in managed UGI like parks.

Keywords Cultural ecosystem services - Tree cover · Urban brownfields · Urban parks

\section{Introduction}

This is the "Urban century"- the world population is increasing, especially in cities, where more than $60 \%$ of the world's population is projected to live by 2050 (United Nations 2014; McDonald et al. 2018). 
Urbanization causes fragmentation and degradation of natural ecosystems, resulting in the reduction of natural landscapes, but also of urban green infrastructure (UGI). UGI provides important ecosystem services, which are crucial for the well-being of urban citizens (Millennium Ecosystem Assessment 2005; European Environment Agency 2014; Kompil et al. 2015). High-quality design and management of UGI and high multifunctional capacities (Liquete et al. 2015) are thus essential to support a diverse urban population. However, to maintain and enhance quality of UGI, more knowledge is needed about its characteristics and biodiversity as well as their relation to the provisioning, regulating and cultural ecosystem services they provide.

UGI is the "network of natural lands, working landscapes and open spaces that provide a range of diverse benefits" (Lovell and Taylor 2013, p. 1448). It contains all planned and managed natural and seminatural landscapes, such as urban parks or forests, allotment gardens, green facades, but also unmanaged green sites like vacant lots and brownfields in cities (European Environment Agency 2014). They provide regulating services like micro-climate regulation, noise reduction or air filtration, that are highly relevant in cities (Bolund and Hunhammar 1999; Elmqvist et al. 2015). In addition, UGI provides important cultural services like nature experiences, recreation and support social cohesion (Dunn et al. 2006; Peters et al. 2010; Rink and Arndt 2011; Breuste et al. 2013; Gómez-Baggethun and Barton 2013; Andersson et al. 2015; Bertram and Rehdanz 2015). These cultural services are embedded in a social-cultural context, often intangible and thus underrepresented in literature (Haase et al. 2014; Hegetschweiler et al. 2017). In contrast to several regulating or provisioning services, cultural services can hardly be assessed by tangible indicators such as yields, biomass or carbon sequestration. Assessing the value of UGI for the provision of cultural services requires a wider indicator spectrum than the frequently-used quantification of available recreation area, especially when it comes to urban ecosystems (MAES 2014). We argue that it is essential to understand spatial, temporal, ecological and social contexts, because cultural ecosystem services and the factors influencing their provision and use directly or indirectly affect the urban dwellers' physical and mental states and, consequently, their quality of life and well-being (Millennium Ecosystem Assessment
2005; Díaz et al. 2015). The actual use of cultural ecosystem services is thereby both influenced by the demand side (i.e. one's socio-cultural and personal characteristics and needs), and by the supply side and thus the characteristics of the UGI itself (Hegetschweiler et al. 2017). Although the availability and accessibility of UGI are among the most important factors influencing their use (Van Herzele and Wiedemann 2003; Schipperijn et al. 2010; Lin et al. 2014), also green and grey features of UGI determine their ecosystem services supply and therefore (potential) use (McCormack et al. 2010; Voigt et al. 2014). In this study, we hypothesize that the actual use of ecosystem services in UGI can be encouraged or discouraged by their green characteristics such as tree cover and plant species diversity to which we refer in this study as green or vegetation parameters.

In urban UGI, tree canopy and density can be an important parameter for people's preferences (Hofmann et al. 2012). Well-maintained urban parks with moderately dense vegetation, for example, seem to provide a sense of safety in societies all over the world, shown in a review about safety aspects in urban green (Sreetheran and van den Bosch 2014). Contrastingly, some urban dwellers, e.g. in Leipzig and Dresden, Germany also appreciate informal sites with low management activities like urban brownfields (Mathey et al. 2016; Pueffel et al. 2018). A study in Norway underpins people's preferences for parks with moderately dense vegetations (Bjerke et al. 2006), and Australian citizens seem to prefer moderate to low levels of tree canopy for recreational use (Shanahan et al. 2014). At the same time, researchers in Baltimore, USA, found that tree cover positively influences social relations and interactions (Holtan et al. 2014). Besides ecosystem services, UGI can also provide disservices, which can be caused by certain species or (dense) vegetation structures (GómezBaggethun and Barton 2013). They may cause especially women to feel unsafe (Koskela and Pain 2000) or contain plant species that provoke allergies (D'Amato 2000; Ćwik et al. 2018). In addition to tree or vegetation density, it seems that species richness in vegetation, often connected to colours of flowering species (Lindemann-Matthies et al. 2010), is positively related to aesthetic appreciation and people's well-being (Fuller et al. 2007; Dallimer et al. 2012). However, there is a lack of research providing empirical evidence of how green parameters of UGI 
can influence the actual use of specific cultural and other ecosystem (dis-)services by urban dwellers.

This study assessed the use of cultural as well as provisioning and regulating services in 36 sites of UGI in the city of Leipzig, Germany, evaluating relations between green parameters such as tree cover or plant diversity and use. Due to the unique situation of plenty of available brownfields in the city, of which some are intensively used for recreation (Pueffel et al. 2018), we decided for two types of UGI: urban parks and urban green brownfields. We asked visitors to identify ecosystem services that were used at the studied UGI sites. The following research questions are addressed in this paper:

(1) Does tree cover influence visitor density and ecosystem service use of respondents in UGI?

(2) How do visitor density and ecosystem service use of respondents differ between parks and brownfields?

(3) Which other "green" parameters influence ecosystem service use in UGI?

\section{Material and methods}

Study region and study site selection

We conducted the study in the city of Leipzig in Saxony, Germany, with an area of about 30,000 ha and currently almost 600,000 inhabitants (Stadt Leipzig 2019). The city was affected by massive population loss and by increasing numbers of vacant apartments and unused brownfields after the German reunification in 1990 (Haase, 2008). Population losses slowed down and stabilized after the turn of the millenium. Since 2012 the city has been growing again, currently by around 10,000 citizens ( 2\%) per year. Consequently, pressures on the city's remaining open spaces are strongly increasing (Stadt Leipzig 2019). Unused spaces of former industrial sites or residential buildings have now become opportunities for residential and commercial development (European Environment Agency 2015) but also support urban biodiversity and provide recreational services. The latter complement the multitude of public parks, public green areas and allotment gardens. Leipzig also benefits from protected riparian forests, stretching from the south towards the north-west of the city, which are intensively used by residents for recreational activities.

In this study, we selected public parks that are maintained on a regular basis and green brownfields which are unmanaged, but registered in a brownfield cadastre by the city of Leipzig, thus representing two typical types of UGI in Leipzig (Stadt Leipzig 2017b). Some of the latter are maintained by private owners or residents. We then determined the share of tree cover relating to mature trees higher than $5 \mathrm{~m}$ (EUNIS category) for every park and every brownfield on the basis of analysed digital orthophotos of June 2012 and a digital surface model of 2010 (Banzhaf et al. 2018). Next, we grouped parks as well as brownfields into three classes of tree cover: low (0-33\%), medium $(>33-67 \%)$ and high $(>67-100 \%)$. We then selected 18 urban parks and 18 brownfields via a stratified random sampling: six sites for each tree cover class. Brownfields had to be accessible, i.e. not completely surrounded by walls or fences and were not overgrown by shrubs. We selected all study sites within a $5 \mathrm{~km}$ radius from the city centre. This procedure yielded 36 study sites in six groups of 6 replicates: parks with low, medium and high tree cover $\left(\mathrm{P}_{\text {low }}, \mathrm{P}_{\text {med }}, \mathrm{P}_{\text {high }}\right)$, and brownfields with low, medium and high tree cover $\left(\mathrm{B}_{\text {low }}, \mathrm{B}_{\text {med }}, \mathrm{B}_{\text {high }}\right)$. Figure 1 shows the distribution of study sites and some examples of green brownfields in Leipzig.

Biodiversity and other green measurements

ArcGIS (version 10.6) was used to generate randomly distributed points representing the centre of $15 \times 15 \mathrm{~m}$ sample plots on all study sites. The total area of these sampling plots (minimum two sampling plots for each site) covered at least $1 \%$ of the total area of the park or brownfield (Hermy and Cornelis 2000). Within these sample plots, we identified all woody species at a height of $2 \mathrm{~m}$ or above. On small brownfields $<0.65$ ha (size of the smallest park, $\mathrm{n}=9$ ), all present woody species at a height of $2 \mathrm{~m}$ or above were mapped. Richness in woody species was analysed for tree richness $(\geq 5 \mathrm{~m})$ and shrub richness $(<5 \mathrm{~m})$ and scaled to richness per $100 \mathrm{~m}^{2}$ for each study site. We used these values to compare all study sites of different sizes including varying sizes of mapped area. In addition to woody species, we identified all herbaceous species that were flowering at the time of mapping. These were also identified 
within the same $15 \times 15 \mathrm{~m}$ plots in parks and large brownfields or in two $5 \times 5 \mathrm{~m}$ random plots on small brownfields. We determined their species, height, coverage (after Braun-Blanquet) and flowering colour (Strath et al. 2007). Flowering richness was also scaled to richness per $100 \mathrm{~m}^{2}$. All vegetation assessments were conducted in August and September 2017. In the field, we additionally estimated the presence of the following land use/land cover types at our observation sites for ecosystem service use (see "Use of ecosystem services" section) mapping: grassland/meadow, ruderal grassland, woodland/trees, shrubs, water bodies, urban gardening structures and flowerbeds. We then calculated the landscape structure diversity (value 1-7) by summing up the presence or absence of each of these land use/land cover types. In addition to on- site characteristics, we calculated available public green spaces and inhabitant density within $300 \mathrm{~m}$ in GIS, representing an average walking distance of 5 min to each study site (Barbosa et al. 2007). To do so, we used a dataset of public green spaces (Stadt Leipzig 2017a) and population data on statistical block level from the city of Leipzig (Stadt Leipzig 2018).

\section{Use of ecosystem services}

To map ecosystem service use throughout the day, we defined four time slots: morning (8-11), noon (11-14), afternoon (14-17) and evening (17-20). Each of the 36 study sites was visited twice in each time slot from April to September 2018. Field visits were set within the time slot limits and lasted $2 \mathrm{~h}$ during the first
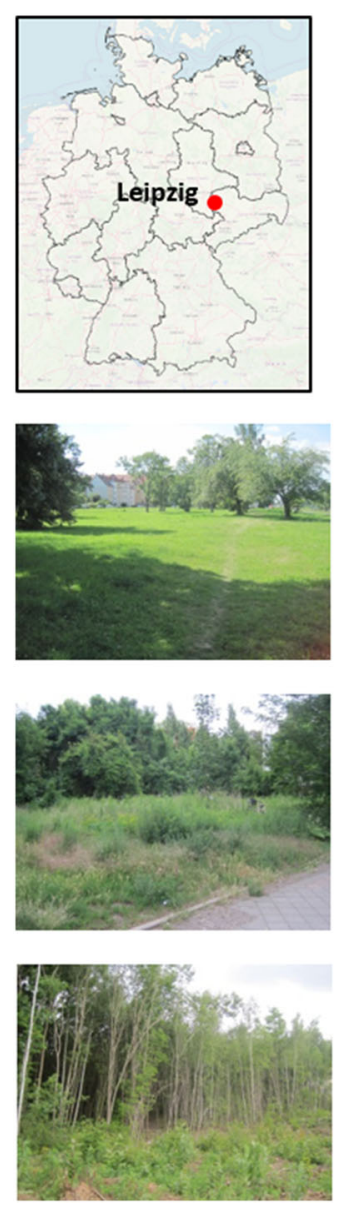

Fig. 1 Map of the city of Leipzig and study sites in Leipzig within a $5 \mathrm{~km}$ radius from the city centre. We assessed ecosystem service use in 18 urban parks (green) and 18 urban brownfields (brown) with varying tree cover. Left column:

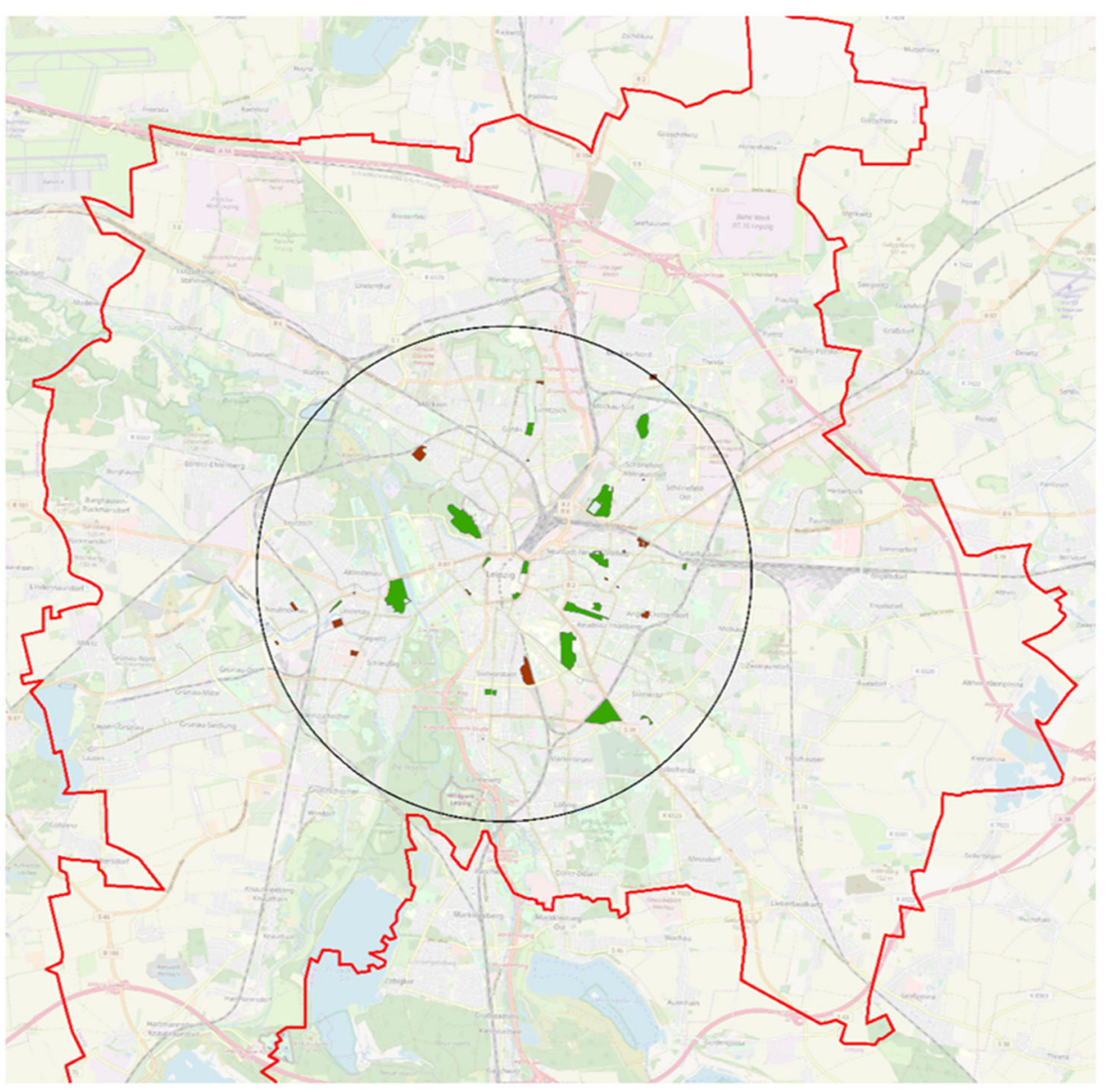

Location of Leipzig in Germany, followed by examples of green brownfields with low, medium, high tree cover (from top to bottom). Map source: (COpenStreetMap \& contributors; Photos: J. Palliwoda 
mapping period (April-July) and $1 \mathrm{~h}$ in the second mapping period (August-September). In total, each site was observed for $12 \mathrm{~h}$. We organised our study site visits during weekdays and weekends in a fashion that each site was observed twice on weekends and six times on weekdays. Ecosystem service use assessments were not carried out during inclement weather. Assessments were performed on observation sites clearly delineated by paths or other landmarks such as shrub formations or walls. We distinguished two main indicators to describe ecosystem service use:

1. Visitor density quantifying the total number of observed and interviewed visitors and their primary activity (visitors $*$ hectare $^{-1} *$ hour $^{-1}$ )

2. Proportion of used ecosystem service groups among respondents of surveys (number of users for ecosystem service group * total number of respondents ${ }^{-1}$ )

\section{Visitor density}

We counted all people entering the observation site and their visible primary activity to calculate total use density for each site. Observed ecosystem service use was limited to visible activities like biking, walking, jogging, dog walking or sitting (included in "Other activities"), some aesthetical and experiential services (e.g. watching ducks) and societal relations (e.g. picnicking, groups of people). Observed use of regulating and most experiential and aesthetical services could only be assessed when visitors were part of a group of which at least one person was surveyed. The rest of the group was then counted as using the same ecosystem service.

\section{Share of used ecosystem service groups from surveys}

Within the observation sites, we randomly selected adults and teenagers (older than 14 years), by asking persons every fifth minute. All respondents apparently younger than 14 years were classified as children and only interviewed when they were in company of adults. For the assessment, we adapted a questionnaire based on the MapNat smartphone application ${ }^{1}$ (Priess and Kopperoinen 2016). Ecosystem service definition

\footnotetext{
${ }^{1}$ MapNat is available at google playstore.
}

and its aggregation included in MapNat are based on the common international classification of ecosystem services (CICES) (Haines-Young and Potschin 2013). As most citizens are unfamiliar with the term "ecosystem service", the term was avoided in the app and the app-based survey. For our questionnaire, we selected 24 out of 30 ecosystem services available on MapNat and six out of nine problems (disservices) that were relevant for urban areas (Appendix A in Supplementary Materials). Respondents were asked to select the most relevant ecosystem service or disservice they were using or felt disturbed by at that moment. The questionnaire was followed by a closedend question about what motivated them to choose this place (six categories: Nature/landscape or wilderness, tranquillity or seclusion, physical space for activity, social or cultural interaction, close to home or accessible, other motivations). Finally, we asked for socio-demographic data (age, gender, place of living). The respondents who replied as using the sites just as shortcuts and who did not choose any ecosystem service were excluded from the analysis. Due to the fact that only two respondents stated disservices, we excluded disservices from our analysis.

\section{Data classification and statistical analysis}

All data were processed in $\mathrm{R}$, version 3.6.0. For the analysis we aggregated the 20 ecosystem services used by visitors into the following seven groups: provisioning services, regulating services, physical interactions, dog walking, biking, social relations and experiential and aesthetical ecosystem services. Provisioning services include all kinds of collecting food or material. We are aware that other authors have addressed them as recreational services (e.g. Plieninger et al. 2013). Nevertheless, we decided to classify them as provisioning services to represent the diversity of ecosystem services use on our study sites. We aggregated most activities that represent recreational services (walking, sport fishing, jogging and other uses) as physical interactions (with nature) (HainesYoung and Potschin 2013). However, two of them were predominant in our sites (biking in parks and dog walking on brownfields) and were thus kept as single categories. Picnicking and barbecuing were classified as social relations because sites served as meeting points with other people (Plieninger et al. 2013). 
We applied pairwise Kruskal-Wallis one-way Analysis of Variance (ANOVA) for both UGI types on a $95 \%$ confidence interval assuming as a null hypothesis that species richness and used ecosystem service groups were independent of the tree cover class. To test the relationship between motivations for site use and tree cover class, we used chi-square tests of independence including their Pearson's residuals of each factor level.

To examine possible relationships between green parameters towards both indicators, (i) total visitor density and for (ii) proportion of each ecosystem service group used by respondents, several linear or generalised linear models (GLM) were performed, depending on the normality of residuals, with a $95 \%$ confidence interval. For modelling visitor density (count data), we chose quasipoisson, and for proportions of ecosystems service group uses, we specified quasibinomial link functions for the GLM or used a logit transformed response for the linear model. Regressions for ecosystem service groups could only be performed if they were used in at least ten sites per UGI type (= ten replicates). Due to the fact that most aggregated ecosystem service groups were used on less than ten brownfields, we did not perform regression analysis for survey results on brownfields except for dog walking. We used the following green parameters as predictors for the regressions: share of tree cover (0-1), landscape structure diversity (1-7), tree richness (species per $100 \mathrm{~m}^{2}$ ), shrub richness (species per $100 \mathrm{~m}^{2}$ ), flowering richness (species per $100 \mathrm{~m}^{2}$ ), and alternative public green space in a distance of $300 \mathrm{~m}$ (ha).

To display all linear correlations between green characteristics (explanatory variables) and observed ecosystem service groups (response variables) being used in parks and brownfields, we performed a redundancy component analysis (RDA) for both UGI types with all green parameters and size of the site (in hectare) as constraining (explaining) variables. The RDA summarises combinations of all the green parameters into components that best explain variation on the Hellinger transformed (referring to proportions rather than total counts) user density of each ecosystem service group for 18 parks and 18 brownfields (Kindt and Coe 2005).

\section{Results}

\section{Biodiversity}

We identified 78 species (408 mapped woody individuals) in parks and 67 species (1824 mapped individuals) on brownfields, indicating higher woody species richness in parks. Table 1 shows the mean values for all richness values for three tree cover classes in parks and brownfields. Tree richness per 100 $\mathrm{m}^{2}$ increases with increasing tree cover for both types. We found more flowering species per area in all brownfields than in parks. The ANOVA shows significant differences for tree richness between sites of $\mathrm{B}_{\text {low }}$ and $\mathrm{B}_{\text {high }}(p=0.04)$ and for flowering richness between $\mathrm{B}_{\text {med }}$ and $\mathrm{B}_{\text {high }}(p=0.04)$. Flowering richness also differs significantly between parks and brownfields $(p=0.01)$ and is higher in all brownfields. Flowering richness increases with decreasing tree cover in parks.

Visitor density and observed ecosystem service use

We observed more than 20,000 visitors on all study sites (8356 women; 8963 men; 2313 children and 3 people with diverse gender). For all tree cover classes we mapped the highest user densities in parks during afternoons and evenings. Brownfields were used mainly at noon/morning and in the evening and least in the afternoon. In four brownfields, of which three were sites with high and one with medium tree cover, we did not see any users during the observation periods. In parks, gender distribution of male and female visitors was nearly equal, while brownfields were mainly visited by men (65\% male users on average), especially $B_{\text {high }}$ on which only $24 \%$ of users were female (Table 2). Biking and physical interactions (mostly walking) dominated ecosystem service use in parks, while a smaller fraction of citizens used other ecosystem service groups (Fig. 2a). Brownfields were predominantly frequented by citizens walking their dogs and physical interactions (mostly walking or other nature uses such as reading or playing table tennis). Regulating services like mediation of noise or providing shade and shelter are used on brownfields of all tree cover classes (Fig. 2b). Brownfields also provide space for social relations like meeting people ( $10 \%$ of all observed users in $\mathrm{B}_{\text {low }} ; 6 \%$ 
Table 1 Mean richness of tree, shrub and flowering species per tree cover class (low, med, high) per $100 \mathrm{~m}^{2}$ in parks $(\mathrm{P})$ and brownfields (B); (n per group $=6$; total $\mathrm{n}=36$ )

\begin{tabular}{llllc}
\hline Group & $\begin{array}{l}\text { Mean tree richness } \\
\text { per } 100 \mathrm{~m}^{2}\end{array}$ & $\begin{array}{l}\text { Mean shrub richness } \\
\text { per } 100 \mathrm{~m}^{2}\end{array}$ & $\begin{array}{l}\text { Mean flowering } \\
\text { richness per } 100 \mathrm{~m}^{2}\end{array}$ & $\begin{array}{r}\text { Tree cover } \\
\text { range in \% }\end{array}$ \\
\hline $\mathrm{P}_{\text {low }}$ & 0.74 & 0.51 & 1.26 & $0-33$ \\
$\mathrm{P}_{\text {med }}$ & 0.85 & 0.38 & 0.4 & $>33-67$ \\
$\mathrm{P}_{\text {high }}$ & 1.04 & 0.44 & 0.19 & $>67-100$ \\
$\mathrm{~B}_{\text {low }}$ & 0.31 & 0.46 & 7.85 & $0-33$ \\
$\mathrm{~B}_{\text {med }}$ & 0.8 & 0.44 & 8.43 & $>33-67$ \\
$\mathrm{~B}_{\text {high }}$ & 1.2 & 1.12 & 1.37 & $>67-100$ \\
\hline
\end{tabular}

in $\mathrm{B}_{\text {high }}$, Table 2). With increasing tree cover, we counted fewer visitors in both UGI types (Table 2), though calculated brownfield visitor densities show that most people per hectare were counted on sites with high tree cover (Fig. 2b). It is noteworthy that only three out six observed $\mathrm{B}_{\text {high }}$ were used at all and thus $\mathrm{B}_{\text {high }}$ is actually less used than $\mathrm{B}_{\text {med }}$ and $\mathrm{B}_{\text {low }}$. We tested landscape structure diversity, tree cover and species richness (tree, shrub and flowering richness) as predictors for visitor density in separated regressions for both types and found no significant influence. Instead, inhabitant density within $300 \mathrm{~m}$ showed a slight positive significant influence on total visitor density in parks $(\beta=0.00014$, explained variance $=0.31, p=0.02$ ). For brownfields, we found no significant influence on visitor density.

\section{Ecosystem service use by respondents}

Of the approximately 19,600 observed park visitors, we interviewed 1624 citizens of whom 778 were female, 760 were male, two were diverse gender and 84 were children. On brownfields, we asked 255 people out of 620 observed visitors (105 women, 135 men, two diverse, 13 children). In total, we managed to ask about $41 \%$ of observed brownfield users. In parks, only $8 \%$ of the users were asked (see also Appendix B in Supplementary Materials). After excluding respondents using the UGIs only as shortcuts, we analysed 1500 surveys for parks and 250 for green brownfields.

In parks, we recorded 20 different ecosystem services used by respondents. The main activities of respondents in all parks were walking (24\% of respondents), dog walking (15\%), other activities in nature (e.g. playing football or reading-13\%) and enjoying landscape beauty (11\%). Physical interactions, where urban ecosystems provide space for several activities walking, jogging or other nature uses, were the most important group among park respondents in all three tree cover groups. The linear regression of tree cover as a predictor for proportions of physical interactions shows a significant, slightly negative relationship ( $p=0.01$ ) illustrating increasing physical interactions in parks with decreasing tree cover (Fig. 3). Although regulating services were used in all tree cover classes of parks, we mapped a slight increase with increasing tree cover $\left(13 \%\right.$ in $\mathrm{P}_{\text {low }}, 20 \%$ in $\left.\mathrm{P}_{\text {high }}\right)$. The use of providing shade and shelter, for example, increases with higher levels of tree cover (3\% in $\mathrm{P}_{\text {low }}, 4 \%$ in $\mathrm{P}_{\text {med }}$ and 9\% in $\mathrm{P}_{\text {high }}$ ). The linear regression with tree cover as predictor for the share of used regulating ecosystem services shows a positive but not significant influence of tree cover.

Experiential and aesthetical services did not show a linear relationship to tree cover but were most frequently enjoyed by respondents in parks with medium tree cover (26\% of respondents). However, the ANOVA showed no significant differences in experiential and aesthetical ecosystem service use between tree cover groups. The fact that two out of six parks with medium tree cover contain water bodies may have influenced the high shares of experiential uses. Watching animals or plants were often performed at ponds (e.g. feeding ducks). When testing other green parameters as predictors in separated regressions, neither of them showed a significant influence on any ecosystem service group use.

Citizens on urban brownfields used 14 different ecosystem services. Sites were mainly visited for dog walking $\left(65 \%\right.$ of respondents in $\mathrm{B}_{\text {low }}, 27 \%$ in $\mathrm{B}_{\text {med }}$, 


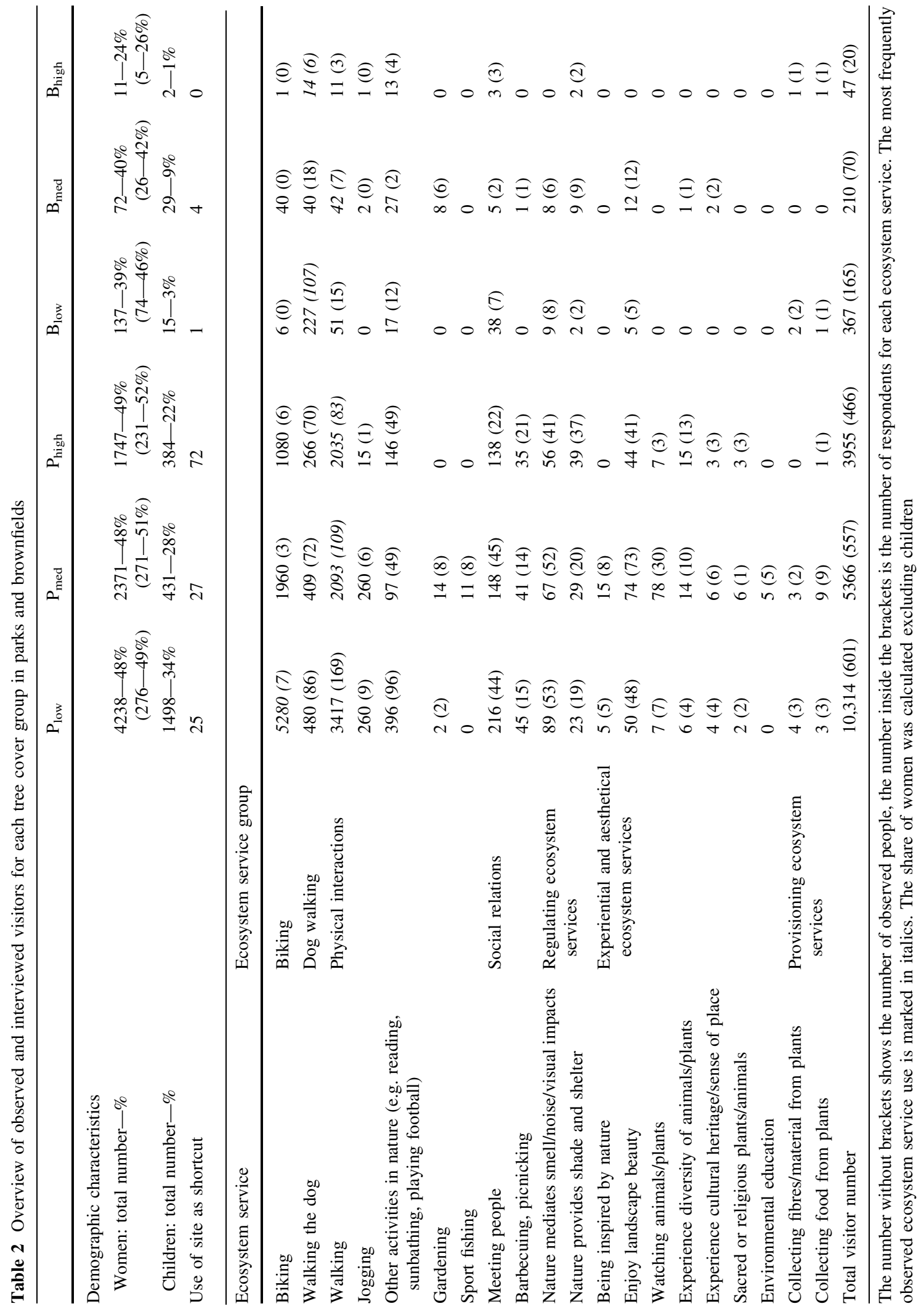




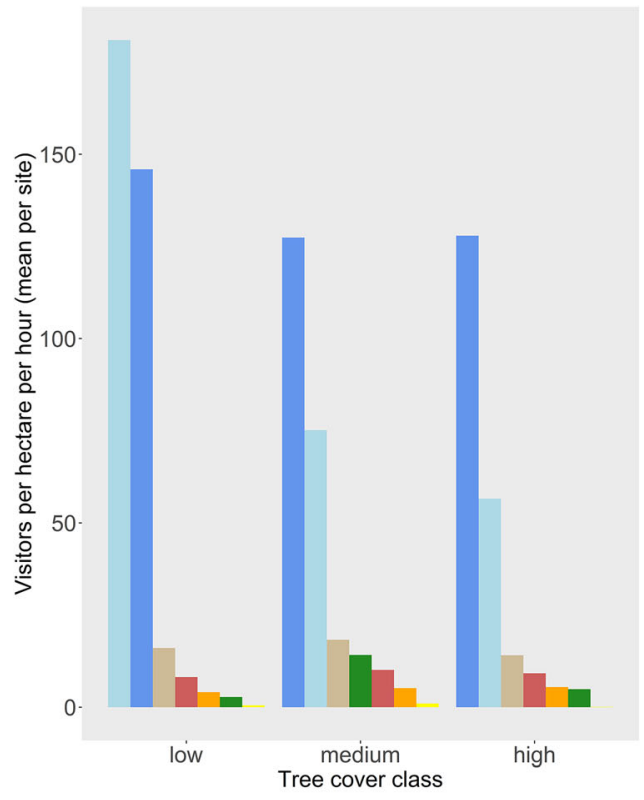

(a) Parks

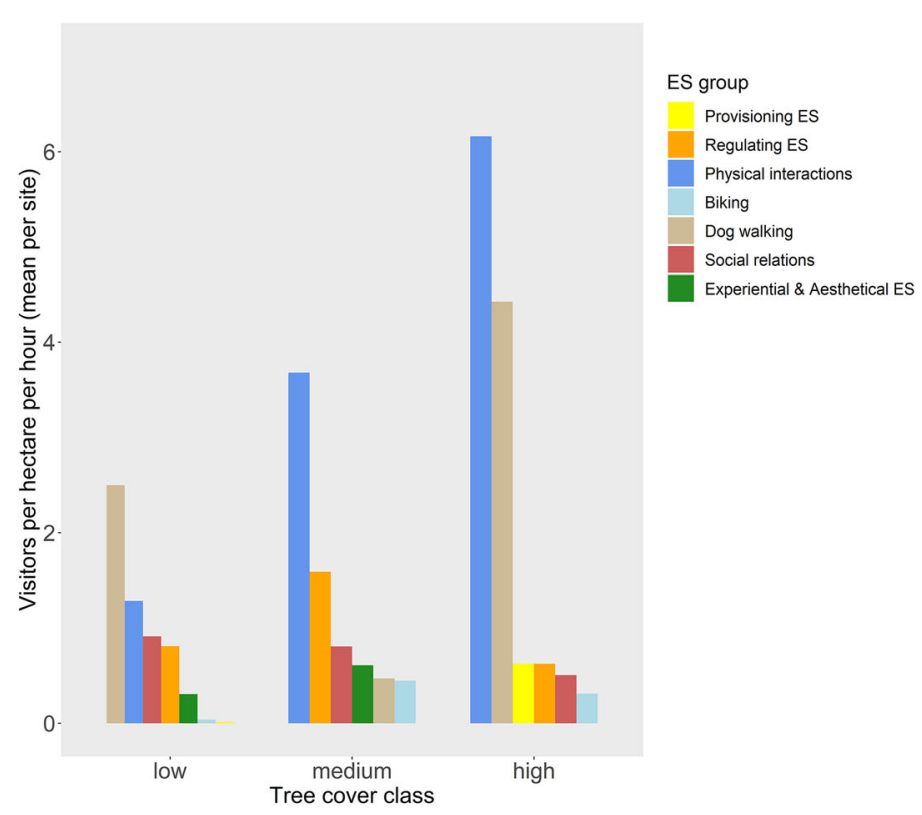

(b) Brownfields
Fig. 2 Mean visitor density of all users (observed and interviewed) and their ecosystem service (ES) group use for (a) parks and (b) brownfields with three tree cover classes (low, medium, and high). Users are scaled to person $*$ hectare $^{-1} *$

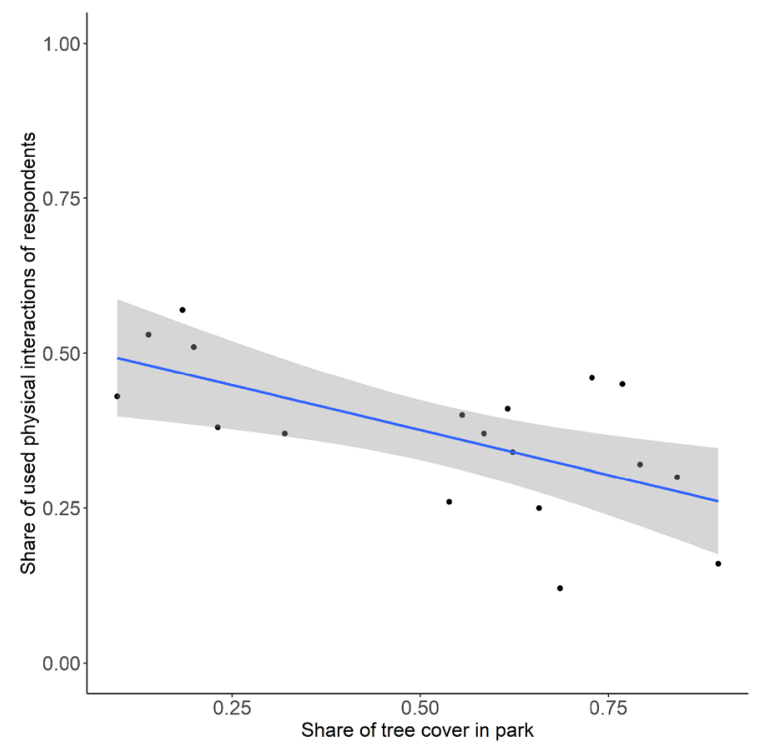

Fig. 3 Linear model with tree cover as explaining variable for the share of physical interactions that were used by interviewees in all parks (response) showing a significant negative influence $\left(\beta=-1.35, p=0.008, \mathrm{R}^{2}=0.36\right.$, adj $\left.\mathrm{R}^{2}=0.32\right)$ The shaded area represents the confidence interval for the response variables hour $^{-1}$; means are calculated only for sites used by visitors. Please note the different ordinate axis scales of parks and brownfields

$30 \%$ in $\left.\mathrm{B}_{\text {high }}\right)$. Brownfields were furthermore used for walking (10\% on average) as well as for their regulating services $\left(6 \%\right.$ in $\mathrm{B}_{\text {low }}, 23 \%$ in $\mathrm{B}_{\text {med }}, 10 \%$ in $\left.\mathrm{B}_{\text {high }}\right)$. The share of respondents mentioning aesthetical or experiential services was highest on $\mathrm{B}_{\text {med }}$ (23\%) (Fig. 2b). We did not find significant differences between tree cover groups or significant influence of tree cover on dog walking activities. Some of the users of brownfields where also consuming illegal drugs, which we aggregated in the category "Other activities in nature".

\section{Motivation for site use}

In addition to the use of ecosystem services, we asked respondents to choose from six motivation categories, why they used the particular park or brownfield for the specified ecosystem service. Results show that "Close to home or accessible" as the most frequent motivation mentioned by visitors of both UGI types (59-66\% of respondents in parks, 35-46\% on brownfields, Fig. 4). To reveal differences of proportions of motivation categories between the three tree cover groups, we applied chi-square tests and found 


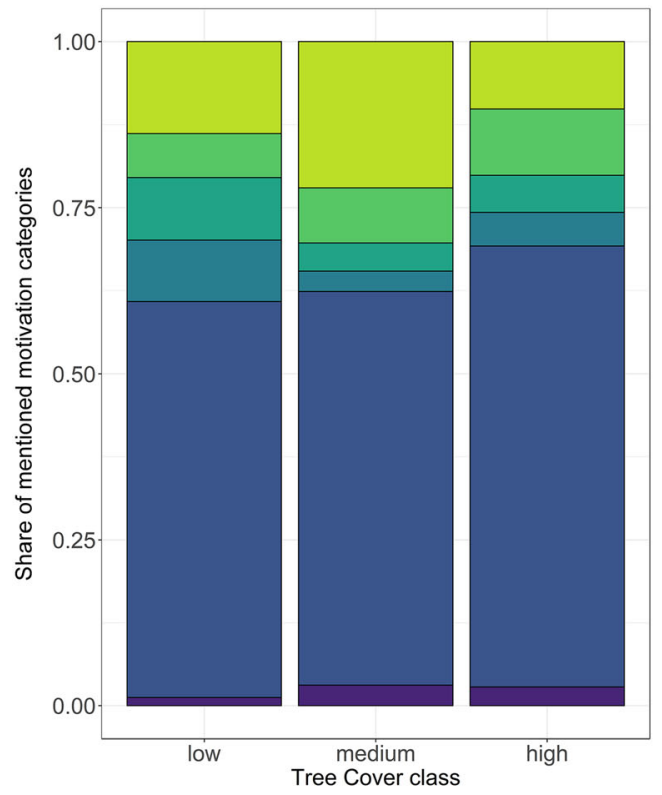

(a) Parks

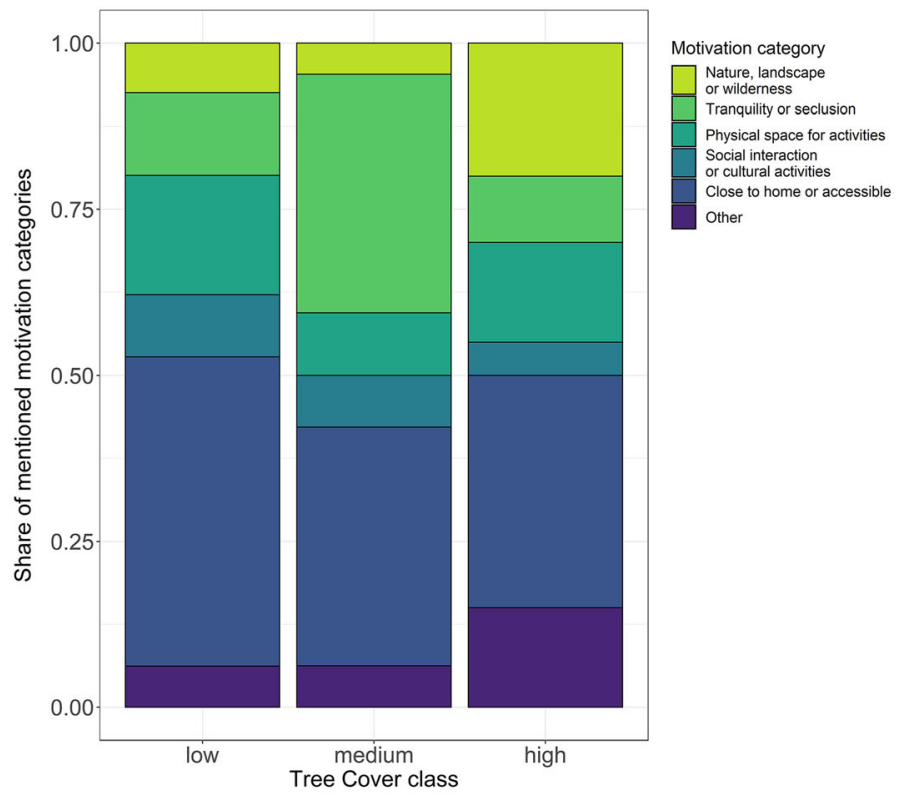

(b) Brownfields
Fig. 4 Respondents and their motivation to visit (six predefined categories) for (a) Parks with low tree cover $(n=572)$, medium tree cover $(n=518)$ and high tree cover $(n=393)$ and

significant differences for both types $(p<0.001)$. Differences between tree cover groups in parks are mainly caused (highest Pearson's residuals) by the categories "Nature, landscape or wilderness" being most frequently chosen in $\mathrm{P}_{\text {med }}$ (22\% of respondents) and "Social or cultural interaction" stated more often in $\mathrm{P}_{\text {low }}(9 \%)$ than in $\mathrm{P}_{\text {med }}(3 \%)$ and $\mathrm{P}_{\text {high }}(4 \%)$ as Fig. 4a displays. On brownfields, the category "Tranquillity or seclusion" shows high variation between tree cover classes, with a strong dominance in $\mathrm{B}_{\text {med }}$ (35\%) compared to $\mathrm{B}_{\text {low }}$ and $\mathrm{B}_{\text {high }}$ (Fig. 4b). Comparing both UGI types independently from their tree cover class, we found significant differences $(p<0.001)$, e.g. were "Tranquillity or seclusion" and "Physical space for activities" more important to brownfield users (18\% and $16 \%$ on brownfields vs. $8 \%$ and $7 \%$ in parks).

Influence of other green parameters on observed ecosystem service use

Figure 5 shows the results of the redundancy analysis (RDA) and Table 3 the loadings for the first three components of the RDA explaining $68 \%$ of the variance ( $p=0.003$ on 1000 permutations). The size for $(\mathbf{b})$ Brownfields with low tree cover $(\mathrm{n}=161)$, medium tree cover $(n=64)$, and high tree cover $(n=20)$. Data include only valid answers for motivation

and the presence of public green space within $300 \mathrm{~m}$ distance of the study site contribute most and are the only significant variables for the first component (explaining 49\%). The loading for shrub richness is highest in the second component (explaining 16\%). Biking activities are positively related to increasing area of public green space within $300 \mathrm{~m}$. Physical interactions were associated with small parks, while most other ecosystem service groups, especially dog walking and aesthetical and experiential services are expected in large parks that go along with higher values of landscape structure diversity and contain higher richness in shrub species. When performing the RDA with the same constraining variables for brownfields, we found $48 \%$ of the variance explained by the components (Figure and loadings displayed in Appendix C in Supplementary Materials), although no environmental variable was tested significant. For brownfields, size was one of the most important explaining variables; especially dog walking was often observed on large brownfields. 


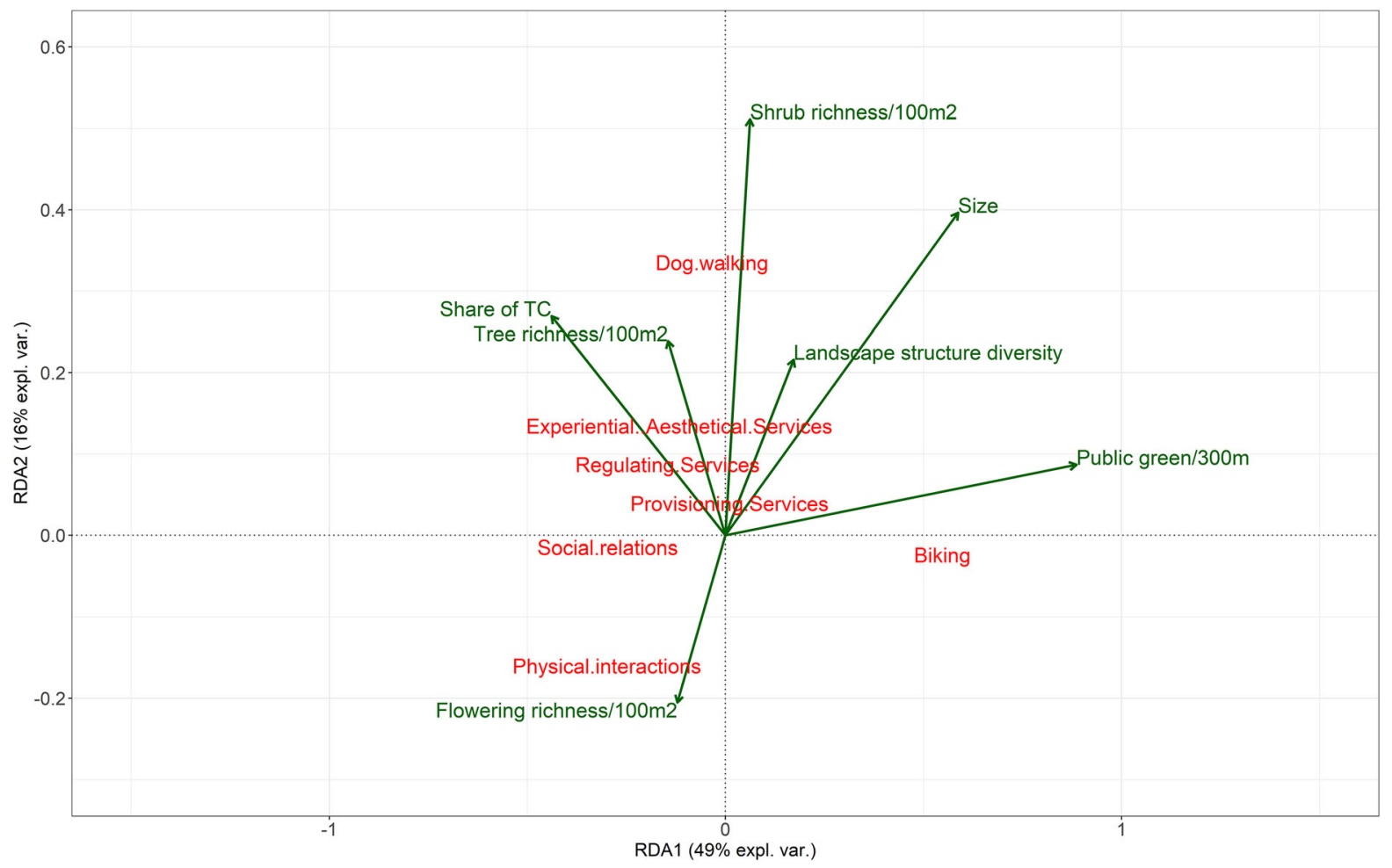

Fig. 5 Graphics of the first two RDA axes for parks, scaling method 2. Combined they explain $65 \%$ of the total variance

Table 3 Loadings of the first three components (scaling method 2) that explain $68 \%$ of the total variance

\begin{tabular}{lcrr}
\hline Variable & RDA1 & RDA2 & RDA 3 \\
\hline Size & $0.59^{*}$ & 0.40 & -0.38 \\
Tree richness $/ 100 \mathrm{~m}^{2}$ & -0.15 & 0.24 & 0.55 \\
Public green within $300 \mathrm{~m}$ & $0.89^{* *}$ & 0.09 & 0.28 \\
Share of tree cover & -0.44 & 0.27 & 0.09 \\
Flowering richness $/ 100 \mathrm{~m}^{2}$ & 0.12 & -0.21 & -0.28 \\
Shrub richness $/ 100 \mathrm{~m}^{2}$ & 0.06 & 0.51 & 0.02 \\
Landscape structure diversity & 0.17 & 0.22 & 0.58 \\
Cumulative proportion of explained variance & 0.49 & 0.65 & 0.68 \\
\hline
\end{tabular}

The highest and and/or significant loadings in each component are marked in italics

Significance levels: $*<0.05 ; * *<0.01 ; * * *<0.001$

\section{Discussion}

Urban parks and brownfields in Leipzig are used for various cultural ecosystem services as well as regulating services such as providing shade or reducing noise. We found that citizens are mainly motivated to use particular sites of UGI by proximity to their home and inhabitant density in the surrounding area as an important variable increasing total visitor density or, in other words, the use of public parks. Thus, proximity to accessible UGI should be a key element of green space planning in cities (Wolch et al. 2014) to increase distributional justice for densely populated districts and provide ecosystem services for all citizens. Besides inhabitant density, our study provides findings how vegetation parameters, especially 
tree cover, can influence the use of ecosystem services in UGI.

Biking and physical interactions such as walking and other activities in nature (e.g. reading, sunbathing) predominated ecosystem service use in urban parks, which confirms findings from other European studies (Bertram and Rehdanz 2015; Bijker and Sijtsma 2017; Rall et al. 2017). While in Leipzig physical interactions seem to be favourably used in small parks with low tree cover, the positive association between large parks and enjoying experiential and aesthetical as well as regulating services points to the importance of a high landscape structure diversity as it can be found in spacious multifunctional UGI (Schipperijn et al. 2010; Voigt et al. 2014). Although not statistically significant, we found tree cover positively related to uses of regulating services that are provided by UGI. Our findings underline the importance of shaded areas in public UGI supporting temperature regulation that is highly relevant in UGI (Jim and Chen 2006; Voigt et al. 2014; Riechers et al. 2016) and, at the same time, facilitating physical activities (Timperio et al. 2008). We also point out the accompanying availability of spacious open areas that encourage sporting activities and other physical interactions (Ćwik et al. 2018). High visitor densities and more aesthetical and experiential uses on sites with medium tree cover, confirmed by other studies, reflect the finding that UGI visitors seem to prefer moderately dense vegetation (Kaplan and Kaplan 1989; Bjerke et al. 2006; Lafortezza et al. 2008; Shanahan et al. 2014).The latter findings go hand in hand with the frequent mentioning of "Nature, landscape or wilderness" as motivations to visit $\mathrm{P}_{\text {med, }}$ supporting the assumption that park users prefer UGI designs of mixed open spaces and shaded areas for aesthetical services and nature experiences. These results additionally illustrate diverse tree cover and vegetation structures as important UGI features to ensure the provision of multiple ecosystem services comprising physical interactions for recreation, shade provision and experiential or aesthetical services. The presence of water bodies as UGI components can furthermore increase aesthetical and experiential services (Plieninger et al. 2013). Water bodies are often populated by animals, contributing to the increase in nature interactions and experiences, which are often limited in UGI (Gobster 2007). Previous studies confirm that park users mention water elements in urban green as important and aesthetical features (McCormack et al. 2010; Qiu et al. 2013; Hami and Emami 2015). The integration of water elements in UGI planning can thus contribute to the development of multifunctional green infrastructure in cities. Like other UGI studies, we observed very little use of spiritual or educational services, implying either low demands or the provision by other facilities or institutions like churches (Bertram and Rehdanz 2015), or by ecosystems in non-urban or rural areas (Plieninger et al. 2013; Rall et al. 2017).

Compared to parks, on brownfields we mapped only a small number of bikers, which may be due to the lack of available infrastructure for biking (connecting and smooth paths) (Lu et al. 2019). Our study sites comprised only one $\mathrm{B}_{\text {med }}$ brownfield with a connecting path, which explains the high number of bikers in this group (Pueffel et al. 2018). Most of the studied brownfields were used, especially by citizens who walked their dogs, confirming other studies addressing brownfield use (Rall and Haase 2011; Pueffel et al. 2018). Our findings imply that tree cover seems to be a relevant determinant of brownfield use intensity, as $\mathrm{B}_{\text {low }}$ and $\mathrm{B}_{\text {med }}$ sites were visited more frequently compared to $\mathrm{B}_{\text {high }}$. We also identified the size of the site as an important factor explaining dog walking on brownfields, indicating that large sites were used more often. In contrast to large parks, large brownfields may not provide a higher landscape structure diversity than small brownfields, but just more space which visitors use for instance to unleash their dogs, which is prohibited in public parks and a frequent issue of conflict. Users on brownfields have different priorities and motivations and prefer different UGI properties than park users. Brownfields seem to be less appreciated for their natural elements or landscape diversity, but for providing privacy and opportunities for informal uses (Pueffel et al. 2018). On one $\mathrm{B}_{\text {low }}$ for example, we often interviewed and mapped visitors sitting around a fire as using the site for social relations. For them, the site serves as place to meet with neighbours or friends and where they could light a bonfire, which is not allowed in public parks. The previous examples highlight the seclusion and unregulated character of brownfields as important and desired UGI characteristics. However, the secluded character of dense unmaintained sites may also contribute to facilitate illegal activities and to the perception of low safety (Sreetheran and van den Bosch 2014; Hami and Emami 2015), explaining 
higher user densities on $\mathrm{B}_{\text {low }}$ and $\mathrm{B}_{\text {med }}$, which are perceived as safer than $B_{\text {high. }}$. Only three out of six sites of $\mathrm{B}_{\text {high }}$ were used at all, and in several cases we observed drug abuse. Safety issues, which are strongly related to gender (Sreetheran and van den Bosch 2014), could also explain the gender differences (approx. 65\% male users) we mapped on brownfields, confirming previous studies counting fewer people on woodlands than on open spaces and generally less female than male visitors on brownfields (Rall and Haase 2011; Rink and Arndt 2011). Although some $\mathrm{B}_{\text {high }}$ sites are frequently used by visitors and/or of high ecological value by providing habitat for plant and animals species, public use and acceptance of unmanaged sucession or "urban wilderness" is often low in Leipzig or elsewhere (Breuste 2004; Kowarik 2005; Lafortezza et al. 2008; Rink and Arndt 2011; Shanahan et al. 2014).

\section{Methodological Issues}

Field observation combined with random surveys is suitable for quantifying most resting and moving activities like picnicking, walking or dog walking, selected by visitors as their main current ecosystem service use. We observed the limitations of our approach, for instance, in addressing bikers as it turned out to be difficult to stop them for an interview, resulting in a limited understanding why bikers choose a route through urban parks or brownfields instead of streets perhaps to avoid street noise, benefit from a safer biking environment, or enjoy the green scenery. We limited the mapping of ecosystem service use to the period from 8 a.m. to 8 p.m.and are aware that we only partly captured typical late evening or night time uses such as picnicking or meeting people.

Some UGI visitors use two or more ecosystem services during one visit, for example, enjoying the scenery/beautiful landscape while taking a walk (Shan 2014). As we intended to map actual ecosystem service uses and not the frequently reported ecosystem service potentials, we limited the answer to the main ecosystem service use to avoid that respondents switch perspectives from actual to potential use. This might lead to the underrepresentation of ecosystem services (e.g. environmental education), which are not as tangible as others (e.g. walking) (Plieninger et al. 2013).
The linkage of place-specific diversity values (species richness) and ecosystem service use allows the identification of direct relations between them. However, diversity assessments were conducted one year before the use assessments, potentially limiting the interpretation of the results, for example, due to differing flowering species diversity. Additionally, this paper focuses only on the "green" parameters influencing ecosystem service use in UGI, and we are aware that there are plenty of other important factors.

\section{Conclusions}

Our analysis provides new insight of how citizens actually use different sites of managed and unmanaged UGI with varying tree cover. Public parks that are ideally nearby people's home can provide different ecosystem services for their users depending on their tree cover. Our results confirm that urban parks with diverse tree canopy and vegetation structures, a mixture of open and shaded areas, potentially including water bodies can increase the use of regulatory and aesthetical ecosystem services in UGI and increase nature interactions. Thus, the diversity of tree cover, vegetation structure and landscape elements all contribute to multifunctional ecosystem service provision and use and should be considered in UGI planning and management. In addition to managed urban parks, our results demonstrate that unmanaged green urban brownfields, especially with low to medium tree cover, contribute to the ecosystem service provision by providing partly complementary services. The sites being used for their seclusion exemplarily illustrate the importance for spatial planning to address and to provide space for conflicting ecosystem services. Designated sites for separated activities, areas with low visibility and/or maintenance activities and lawns with different management concepts, for example, can provide spaces for diverse yet potentially conflicting uses. The role of unmanaged sites, be it for dog walking or lovers of urban wilderness, should not be ignored by planners, as the shift of these uses into highly frequented urban parks could lead to increasing conflicts between UGI users (McCormack et al. 2010; Liu et al. 2018). The integration of low-maintained and secluded sites or areas can thus avoid trade-offs between ecosystem services and contribute to multifunctional UGI. 
Acknowledgements Open Access funding provided by Projekt DEAL. The study was part of the UrbanGaia project (https://urbangaia.eu/), which is funded by BiodivErsA, Project Number 01LC1616A. We thank the City's Office of Green Space and Water Courses for their collaboration, supporting study site selection and the access to spatial data. We would like to thank Nina Schwarz for contributing to the study during the initial phase of the project. We thank all the almost 2000 participants of the surveys and the three anonymous reviewers for helping improving the manuscript. Many thanks to Mina Krieger for supporting the field work and Leslie and Ben Jakobs for helping with data digitalization and language editing. Further data digitalization was performed by Zdenka Smutna, Sandra Wilken und Samuel Karrer, and we are thankful for their support.

Open Access This article is licensed under a Creative Commons Attribution 4.0 International License, which permits use, sharing, adaptation, distribution and reproduction in any medium or format, as long as you give appropriate credit to the original author(s) and the source, provide a link to the Creative Commons licence, and indicate if changes were made. The images or other third party material in this article are included in the article's Creative Commons licence, unless indicated otherwise in a credit line to the material. If material is not included in the article's Creative Commons licence and your intended use is not permitted by statutory regulation or exceeds the permitted use, you will need to obtain permission directly from the copyright holder. To view a copy of this licence, visit http://creativecommons.org/licenses/by/4.0/.

\section{References}

Andersson E, Tengö M, McPhearson T, Kremer P (2015) Cultural ecosystem services as a gateway for improving urban sustainability. Ecosyst Serv 12(SI):165-168

Banzhaf E, Kollai H, Kindler A (2018) Mapping urban grey and green structures for liveable cities using a $3 \mathrm{D}$ enhanced OBIA approach and vital statistics. Geocarto Int. https:// doi.org/10.1080/10106049.2018.1524514

Barbosa O, Tratalos JA, Armsworth PR, Davies RG, Fuller RA, Johnson P, Gaston KJ (2007) Who benefits from access to green space? A case study from Sheffield, UK. Landsc Urban Plan 83(2-3):187-195

Bertram C, Rehdanz K (2015) Preferences for cultural urban ecosystem services: comparing attitudes, perception, and use. Ecosyst Serv 12:187-199

Bijker RA, Sijtsma FJ (2017) A portfolio of natural places: using a participatory GIS tool to compare the appreciation and use of green spaces inside and outside urban areas by urban residents. Landsc Urban Plan 158:155-165

Bjerke T, Østdahl T, Thrane C, Strumse E (2006) Vegetation density of urban parks and perceived appropriateness for recreation. Urban For Urban Green 5(1):35-44

Bolund P, Hunhammar S (1999) Ecosystem services in urban areas. Ecol Econ 29:293-301
Breuste J, Schnellinger J, Qureshi S, Faggi A (2013) Urban Ecosystem services on the local level: urban green spaces as providers. Ekologia 32(3):290-304

Breuste JH (2004) Decision making, planning and design for the conservation of indigenous vegetation within urban development. Landsc Urban Plan 68(4):439-452

Ćwik A, Kasprzyk I, Wójcik T, Borycka K, Cariñanos P (2018) Attractiveness of urban parks for visitors versus their potential allergenic hazard: a case study in Rzeszów, Poland. Urban For Urban Green 35:221-229

D'Amato GD (2000) Urban air pollution and plant-derived respiratory allergy. Clin Exp Allergy 30:628-636

Dallimer M, Irvine KN, Skinner AMJ, Davies ZG, Rouquette JR, Maltby LL, Warren PH, Armsworth PR, Gaston KJ (2012) Biodiversity and the feel-good factor: understanding associations between self-reported human well-being and species richness. BioScience 62(1):47-55

Díaz S, Demissew S, Carabias J, Joly C, Lonsdale M, Ash N, Larigauderie A, Adhikari JR, Arico S, Báldi A, Bartuska A, Baste IA, Bilgin A, Brondizio E, Chan KMA, Figueroa VE, Duraiappah A, Fischer M, Hill R, Koetz T, Leadley P, Lyver P, Mace GM, Martin-Lopez B, Okumura M, Pacheco D, Pascual U, Pérez ES, Reyers B, Roth E, Saito O, Scholes RJ, Sharma N, Tallis H, Thaman R, Watson R, Yahara T, Hamid ZA, Akosim C, Al-Hafedh Y, Allahverdiyev R, Amankwah E, Asah ST, Asfaw Z, Bartus G, Brooks LA, Caillaux J, Dalle G, Darnaedi D, Driver A, Erpul G, Escobar-Eyzaguirre P, Failler P, Fouda AMM, Fu B, Gundimeda H, Hashimoto S, Homer F, Lavorel S, Lichtenstein G, Mala WA, Mandivenyi W, Matczak P, Mbizvo C, Mehrdadi M, Metzger JP, Mikissa JB, Moller H, Mooney HA, Mumby P, Nagendra H, Nesshover C, OtengYeboah AA, Pataki G, Roué M, Rubis J, Schultz M, Smith P, Sumaila R, Takeuchi K, Thomas S, Verma M, YeoChang Y, Zlatanova D (2015) The IPBES conceptual framework-connecting nature and people. Curr Opin Environ Sustain 14:1-16

Dunn RR, Gavin MC, Sanchez MC, Solomon JN (2006) The pigeon paradox: dependence of global conservation on urban nature. Conserv Biol 20(6):1814-1816

Elmqvist T, Setälä H, Handel SN, van der Ploeg S, Aronson J, Blignaut JN, Gómez-Baggethun E, Nowak DJ, Kronenberg J, de Groot R (2015) Benefits of restoring ecosystem services in urban areas. Curr Opin Environ Sustain 14:101-108

European Environment Agency (2014) Spatial analysis of green infrastructure in Europe. European Environment Agency, Luxembourg

European Environment Agency (2015) Urban sustainability issues-what is a resource-efficient city? European Environment Agency, Luxembourg

Fuller RA, Gaston KJ, Warren PH, Devine-Wright P, Irvine KN (2007) Psychological benefits of greenspace increase with biodiversity. Biol Lett 3(4):390-394

Gobster PH (2007) Urban park restoration and the "Museumification" of nature. Nat Cult 2(2):95-114

Gómez-Baggethun E, Barton DN (2013) Classifying and valuing ecosystem services for urban planning. Ecol Econ $86: 235-245$

Haase D (2008) Urban ecology of shrinking cities: an unrecognized opportunity? Nat Cult 3(1):1-8 
Haase D, Larondelle N, Andersson E, Artmann M, Borgstrom S, Breuste J, Gomez-Baggethun E, Gren A, Hamstead Z, Hansen R, Kabisch N, Kremer P, Langemeyer J, Rall EL, McPhearson T, Pauleit S, Qureshi S, Schwarz N, Voigt A, Wurster D, Elmqvist T (2014) A quantitative review of urban ecosystem service assessments: concepts, models, and implementation. Ambio 43(4):413-433

Haines-Young R, Potschin M (2013) Common International Classification of Ecosystem Services (CICES): consultation on version 4, August-December 2012. EEA Framework Contract No EEA/IEA/09/003

Hami A, Emami F (2015) Spatial quality of natural elements and safety perception in urban parks. International conference on agricultural, ecological and medical sciences (AEMS2015) Feb 10-11, 2015 Penang (Malaysia)

Hegetschweiler KT, de Vries S, Arnberger A, Bell S, Brennan M, Siter N, Olafsson AS, Voigt A, Hunziker M (2017) Linking demand and supply factors in identifying cultural ecosystem services of urban green infrastructures: A review of European studies. Urban Forestry \& Urban Greening 21:48-59

Hermy M, Cornelis J (2000) Towards a monitoring method and a number of multifaceted and hierarchical biodiversity indicators for urban and suburban parks. Landsc Urban Plan 49(3-4):149-162

Hofmann M, Westermann JR, Kowarik I, van der Meer E (2012) Perceptions of parks and urban derelict land by landscape planners and residents. Urban For Urban Green 11(3):303-312

Holtan MT, Dieterlen SL, Sullivan WC (2014) Social life under cover. Environ Behav 47(5):502-525

Jim CY, Chen WY (2006) Perception and attitude of residents toward urban green spaces in Guangzhou (China). Environ Manag 38(3):338-349

Kaplan R, Kaplan S (1989) The experience of nature: a psychological perspective. Cambridge University Press, Cambride

Kindt R, Coe R (2005) Tree diversity analysis. A manual and software for common statistical methods for ecological and biodiversity studies. World Agroforestry Centre (ICRAF), Chennai

Kompil M, Aurambout J, Ribeiro Barranco R, Barbosa A, Jacobs-Crisioni C, Pisoni E, Zulivan G, Vandecasteele I, Trombetti M, Vizcaino M, Vallecillo Rodriguez S, Batista e Silva F, Baranzelli C, Mari Rivero I, Perpina Castillo C, Polce C, Maes J, Lavalle C (2015) European cities: territorial analysis of characteristics and trends - An application of the LUISA Modelling Platform (EU Reference Scenario 2013 - Updated Configuration 2014). Joint Research Centre, EUR 27709

Koskela H, Pain R (2000) Revisiting fear and place: women's fear of attack and the built environment. Geoforum 31:269-280

Kowarik I (2005) Wild urban woodlands: towards a conceptual framework. In: Kowarik I, Körner S (eds) Wild urban woodlands. New perspectives for urban forestry. Springer, Berlin, pp 1-31

Lafortezza R, Corry RC, Sanesi G, Brown RD (2008) Visual preference and ecological assessments for designed alternative brownfield rehabilitations. J Environ Manag 89(3):257-269
Lin BB, Fuller RA, Bush R, Gaston KJ, Shanahan DF (2014) Opportunity or orientation? Who uses urban parks and why. PLoS ONE 9(1):e87422

Lindemann-Matthies P, Junge X, Matthies D (2010) The influence of plant diversity on people's perception and aesthetic appreciation of grassland vegetation. Biol Conserv 143(1):195-202

Liquete C, Kleeschulte S, Dige G, Maes J, Grizzetti B, Olah B, Zulian G (2015) Mapping green infrastructure based on ecosystem services and ecological networks: a Pan-European case study. Environ Sci Policy 54:268-280

Liu J, Xiong Y, Wang Y, Luo T (2018) Soundscape effects on visiting experience in city park: a case study in Fuzhou, China. Urban For Urban Green 31:38-47

Lovell ST, Taylor JR (2013) Supplying urban ecosystem services through multifunctional green infrastructure in the United States. Landsc Ecol 28(8):1447-1463

Lu Y, Yang Y, Sun G, Gou Z (2019) Associations between overhead-view and eye-level urban greenness and cycling behaviors. Cities 88:10-18

MAES (2014) Mapping and Assessment of Ecosystems and their Services. Indicators for ecosystem assessements under Action 5 of the EU Biodiversity Strategy to 2020: 2nd report-final. Technical Report. European Union

Mathey J, Arndt T, Banse J, Rink D (2016) Public perception of spontaneous vegetation on brownfields in urban areasresults from surveys in Dresden and Leipzig (Germany). Urban For Urban Green 29:384-392

McCormack GR, Rock M, Toohey AM, Hignell D (2010) Characteristics of urban parks associated with park use and physical activity: a review of qualitative research. Health Place 16(4):712-726

McDonald RI, Colbert ML, Hamann M, Simkin R, Walsh B (2018) Nature in the urban century-executive summary. The Nature Conservancy, Arlington

Millennium Ecosystem Assessment (2005) Ecosystems and human well-being: synthesis. Island Press, Washington, DC

Peters K, Elands B, Buijs A (2010) Social interactions in urban parks: stimulating social cohesion? Urban For Urban Green 9(2):93-100

Plieninger T, Dijks S, Oteros-Rozas E, Bieling C (2013) Assessing, mapping, and quantifying cultural ecosystem services at community level. Land Use Policy 33:118-129

Priess JA, Kopperoinen L (2016) Citizen science. In: Burkhard B, Maes J (eds) Ecosystem service mapping. PENSOFT, Sofia

Pueffel C, Haase D, Priess JA (2018) Mapping ecosystem services on brownfields in Leipzig, Germany. Ecosyst Serv 30:73-85

Qiu L, Lindberg S, Nielsen AB (2013) Is biodiversity attractive?-On-site perception of recreational and biodiversity values in urban green space. Landsc Urban Plan 119:136-146

Rall E, Bieling C, Zytynska S, Haase D (2017) Exploring citywide patterns of cultural ecosystem service perceptions and use. Ecol Indic 77:80-95

Rall EL, Haase D (2011) Creative intervention in a dynamic city: a sustainability assessment of an interim use strategy for brownfields in Leipzig, Germany. Landsc Urban Plan 100(3):189-201 
Riechers M, Barkmann J, Tscharntke T (2016) Perceptions of cultural ecosystem services from urban green. Ecosyst Serv 17:33-39

Rink D, Arndt T (2011) Urbane Wälder: Ökologische Stadterneuerung durch Anlage urbaner Waldflächen auf innerstädtischen Flächen im Nutzungswandel. Ein Beitrag zur Stadtentwicklung in Leipzig. Helmholtz-Zentrum für Umweltforschung - UFZ, Department Stadt- und Umweltsoziologie, p 142

Schipperijn J, Stigsdotter UK, Randrup TB, Troelsen J (2010) Influences on the use of urban green space-a case study in Odense, Denmark. Urban For Urban Green 9(1):25-32

Shan X-Z (2014) Socio-demographic variation in motives for visiting urban green spaces in a large Chinese city. Habitat Int 41:114-120

Shanahan DF, Lin BB, Gaston KJ, Bush R, Fuller RA (2014) What is the role of trees and remnant vegetation in attracting people to urban parks? Landsc Ecol 30(1):153-165

Sreetheran M, van den Bosch CCK (2014) A socio-ecological exploration of fear of crime in urban green spaces-a systematic review. Urban For Urban Green 13(1):1-18

Stadt Leipzig AfSuG (2017a) Grünflächenkataster Leipzig (GFK) (Cataster of urban green areas, Leipzig)

Stadt Leipzig AfSuG, Abteilung Wasserwirtschaft/ Flächenmanagement (2017b) Brachflächenkataster Leipzig (BFK) (Cataster of brownfields, Leipzig)

Stadt Leipzig AfSuW (2019) Ortsteilkatalog 2018 (Municipal Statistics 2018) (in German)
Stadt Leipzig OM (2018) Einwohnerdaten Leipzig (Population data Leipzig)

Strath S, Isaacs R, Greenwald MJ (2007) Operationalizing environmental indicators for physical activity in older adults. J Aging Phys Activity 15:412-424

Timperio A, Giles-Corti B, Crawford D, Andrianopoulos N, Ball K, Salmon J, Hume C (2008) Features of public open spaces and physical activity among children: findings from the CLAN Study. Prev Med 47(5):514-518

United Nations DoEaSA, Population Division (2014) World urbanization prospects: the 2014 revision, highlights (ST/ ESA/SER.A/352). United Nations DoEaSA, Population Division, New York

Van Herzele A, Wiedemann T (2003) A monitoring tool for the provision of accessible and attractive urban green spaces. Landsc Urban Plan 63(2):109-126

Voigt A, Kabisch N, Wurster D, Haase D, Breuste J (2014) Structural diversity: a multi-dimensional approach to assess recreational services in urban parks. Ambio 43(4):480-491

Wolch JR, Byrne J, Newell JP (2014) Urban green space, public health, and environmental justice: the challenge of making cities ‘just green enough'. Landsc Urban Plan 125:234-244

Publisher's Note Springer Nature remains neutral with regard to jurisdictional claims in published maps and institutional affiliations. 